\begin{tabular}{|ll|}
\hline $\begin{array}{l}\text { Social Work/Maatskaplike Werk Vol } 57 \text { No 2; Issue } 5 \\
\text { http://socialwork.journals.ac.za/pub }\end{array}$ & doi:http://dx.doi.org/10.15270/52-2-929 \\
\hline
\end{tabular}

THE ROLES OF SOCIAL AUXILIARY WORKERS IN DROP-IN-CENTRES: ADDRESSING THE BIOPSYCHOSOCIAL NEEDS OF CHILDREN LIVING WITH HIV

Enock Zibengwa, Nontembeko Joyce Bila

South Africa bears the largest burden of children living with HIV in Sub-Saharan Africa. These children battle with multiple vulnerabilities in their lives. This qualitative study explored the roles of ten purposively sampled social auxiliary workers in addressing the biopsychosocial needs of children living with HIV at drop-in centres in Sedibeng District Municipality, South Africa. The study concluded that many of the biopsychosocial needs that children living with HIV face are not being comprehensively addressed. The study proposes the capacitation of social auxiliary workers on paediatric HIV and the biopsychosocial approach as well as improved funding for drop-in centres to increase the depth of services rendered to, and address the growing needs of, children living with HIV.

Keywords: biopsychosocial needs of children living with HIV, children living with HIV, drop-in centre, HIV and AIDS, role and competencies, social auxiliary worker 


\title{
THE ROLES OF SOCIAL AUXILIARY WORKERS IN DROP-IN-CENTRES: ADDRESSING THE BIOPSYCHOSOCIAL NEEDS OF CHILDREN LIVING WITH HIV
}

\section{Enock Zibengwa, Nontembeko Joyce Bila}

\author{
Mr Enock Zibengwa, Department of Social Work and Criminology, University of Pretoria, \\ Pretoria, South Africa. \\ Dr Nontembeko Joyce Bila, Department of Social Work and Criminology, University of Pretoria, \\ Pretoria, South Africa.
}

Keywords: biopsychosocial needs of children living with HIV, children living with HIV, drop-in centre, HIV and AIDS, role and competencies, social auxiliary worker

\section{INTRODUCTION}

South Africa remains the global epicentre of HIV infection, with the total number of people living with HIV estimated at 7.9 million in 2018 (Statistics South Africa [Stats SA], 2018). Although there has been a remarkable decline in new infections especially among children, mainly because of the success in the prevention of mother-to-child transmission (PMTCT), the number of children living with HIV in the country remains a genuine concern. In 2018, 260000 children (aged 0 to 14) were estimated to be living with HIV, with $63 \%$ of these children reported to be on antiretroviral treatment (ART), accounting for the world's largest ART programme, according to the United Nations Programme on HIV/AIDS (UNAIDS, 2019). In a systematic review to ascertain the retention of children living with HIV on ART in HIV care and treatment programmes in Kenya, Mozambique, Rwanda and Tanzania, McNairy, Lamb, Carter, Fayorsey, Tene, Mutabazi, Gusmao, Panya, Sheriff and Abrams (2013) found that these countries did better than South Africa as they managed to initiate and retain 71 to $95 \%$ of children living with HIV on ART. The country therefore needs to speed up ART initiation and retention strategies for all children diagnosed with HIV.

In resource-limited areas of South Africa children living with HIV receive services from drop-in centres. The Children's Act No. 38 of 2005 (as amended) defines drop-in centres as community-based facilities, registered and regulated by the Department of Social Development (DSD), aimed at providing basic services that meet the emotional, physical and social development of vulnerable children. The provision of services within drop-in centres is primarily the responsibility of social auxiliary workers (SAWs), a 'frontline' category of social welfare workforce whose roles are viewed as critical in enabling the identification and facilitation of provision of health and other services to children living with HIV. Social auxiliary work is registered and regulated as a social service profession in terms of the Social Service Professions Act 110 of 1978 (as amended), as well as the Social Work Amendment Act 102 of 1998. In the context of this study, the focus was on SAWs who are employed in drop-in centres serving vulnerable children, including children living with HIV.

Children living with HIV are included in the category of vulnerable children who are found in drop-in centres. It is these researchers' observation that, despite the envisaged critical role that SAWs can play in enabling and facilitating the provision of biopsychosocial services to children living with HIV, the non-standardised and limited HIV knowledge that SAWs possess affects the role and greatly compromises the competencies of this cadre to offer effective services that address the holistic health needs of children living with HIV at the drop-in centres. The lack of HIV knowledge amongst some social service professions lead to HIV-positive children being regarded as akin to other children in need of care and protection, despite clear evidence that these children have unique and special needs (De Jager, 2011; Muchanyerei \& Bila, 2017; Warwick, 2013). It is also important to point out that, despite the availability of a lot of information and research on HIV and AIDS, when it comes to children, the 
information and research are focused mainly on the "affected" children rather than "infected" children (Muchanyerei, 2016:4)

The importance of having a capacitated caregiving workforce that responds competently to the health needs of children living with HIV in community-based facilities, such as drop-in centres, must not be underestimated. Kellerman, Sugandhi, Luo, Mcclure and Yogev (2013) explain that some primary community-based interventions have inadvertently perpetuated poor access to treatment for infected children. The community-based interventions have poor mechanisms to pursue new ideas that are needed to propel programming that diagnoses, links, provides optimal support and retains infected children in care and treatment services. A further assertion made by Kellerman et al. (2013) is that HIV is not just a medical disease but a social one, and as such community-based care programmes designed for children living with HIV should provide comprehensive and integrated activities that are aligned with broader child health services, such as immunisation and nutritional assessments. It is on the basis of these observations that the researchers focused on SAWs as critical personnel in driving programmes in community-based drop-in centres, and explored their roles and competencies in addressing the biopsychosocial needs of children living with HIV.

This article offers a brief overview of the literature, followed by an account of the theoretical framework underpinning the study. Then an outline of the problem statement, research question, research methodology is provided, and the findings, discussion, conclusions and recommendations are presented.

\section{LITERATURE OVERVIEW}

\section{Social auxiliary work}

In South Africa most drop-in centres are staffed by SAWs. The Children's Act No. 38 of 2005 (as amended) is explicit in Section 213 that drop-in centres should implement health, nutrition, educational, parenting, recreational, household economic strengthening and psychosocial care and support programmes that protect and lead to the realisation of improved wellbeing and better health outcomes for children. Thus, the scope of practice of social auxiliary work in drop-in centres is expected to include the implementation of programmes and activities that contribute to the provision of basic and developmental care of children contributing to meeting their physical, emotional, spiritual, cognitive and social needs. Although SAWs in drop-in centres are expected to work under the supervision, instructions and control of trained social workers, in practice they work with very limited supervision because of the shortage of social workers in South Africa (Gray, 2006).

Regarding the development of social auxiliary work in the international context, Kadushin (as cited in Schultz, 2015:26) asserts that, as the social work profession grew, some of the demands that were being placed on "high-level" professionals (social workers) could easily be bridged or addressed by moving "low-level functions" to SAWs who would play the roles of "case-aides" or "social work assistants". Schultz (2015:26) notes that the term "auxiliary worker" was accepted by the United Nations as far back as 1958, when it was described as referring to someone who has been trained in a particular field "with less than professional qualifications and who assists and is supervised by a professional worker".

Literature on the development of SAWs in South Africa is very limited. Most of the few sources that are available are outdated and mainly discuss the history and training of social auxiliary work. Schultz (2015) asserts that the concept of social auxiliary work in South Africa was introduced in November 1991 after an investigation into social work by the Auret Commission of 1976, which revealed that there was a need for the establishment of a category of people to render support services to social workers. Schultz (2015:26) points out that, after a series of discussions and legislative processes, it was the promulgation of the Social and Associated Workers Act (Act 110 of 1978) that led to the recognition of SAWs, who were then called "associated workers".

The importance of social auxiliary work in modern day South Africa is emphasised by Schultz (2015:26), who notes that, "Although the involvement of social auxiliary workers is a historic fact, the need for their 
services has grown significantly over the past few years, especially after the new Children's Act came into being." The author further notes that there is currently an escalation in the successful involvement of SAWs in the non-governmental organisation (NGO) sector as well as in the public sector, particularly within the DSD. Based on increasing demand, the training of SAWs has expanded every year (Schultz, 2015). The promulgation of the South African Qualifications Authority (SAQA) Act in 1995 has seen social auxiliary work being offered as a one-year Further Education and Training Certificate (FETC). This certificate is officially registered by SAQA on the National Qualifications Framework (NQF) as a level-5 higher education qualification. Like social work, the registration, education, training and practice of social auxiliary work is guided, regulated and registered with the South African Council for Social Service Professions (SACSSP), according to the Social Service Professions Act 110 of 1978 (as amended)

\section{Drop-in centres}

Foster (2005:23) notes that, although there is enormous variation in how drop-in centre programmes are implemented, the concept of drop-in centres is now common for "providing the major share of effective and accepted assistance given to Orphans and Vulnerable Children (OVC) and other poorer members of society in sub-Saharan Africa". The drop-in centres where this study took place are described as "important development actors in their own right with huge potential in responding to HIV and AIDS" by the Department of Social Development, (DSD, 2005:20). These drop-in centres were mostly established in communities with high HIV prevalence as a strategy to promote community-based responses that strengthen the participation and involvement of, as well as building resilience in, families and communities in addressing the scourge of the HIV epidemic in the face of limited healthcare resources (DSD, 2005:21; South African National AIDS Council [SANAC], 2017).

The authors noted that in some instances drop-in centres may be supervised by trained professionals such as social workers and psychologists. But, contrary to this expectation, which is usually the case in resource-constrained settings, there is an over-reliance on paraprofessionals, such as SAWs, child and youth care workers and lay volunteers. Foster (2005:26) clarifies that SAWs are "a set of social services cadres with arguably limited training and capacity to make a sustainable impact in the scope and intensity of services rendered to OVC". Thus, gaps remain in service outcomes on aspects such as OVC psychological health, emotional support, child protection and HIV prevention or risk mitigation in those drop-in centres that are managed by paraprofessionals (Foster, 2005).

\section{Children living with HIV}

The United Nations Programme on HIV/AIDS (UNAIDS) (2015:41) states that globally there is limited availability of data on children living with HIV, mainly because "most HIV infections are acquired early in life and are probably undiagnosed". This view is shared by Augusto (2012), who remarks that, despite a successful adult scale-up of testing and treating, the situation of children infected with HIV in South Africa is more concerning as very little is known about them. According to Gray (2009:11), there are no clearly defined "case detection and testing mechanisms" for children, thereby perpetuating the extent of the "hidden HIV paediatric population". The United Nations Programme on HIV/AIDS (UNAIDS) (2019) notes that in 2018 about 260000 children (aged 0 to 14) were estimated to be living with HIV in South Africa.

Richter, Beyrer, Kippax and Heidari (2010:29) observe that, amidst a host of challenges that include poverty, unemployment and global economic recession, South Africa is one of the Sub-Saharan countries that are struggling with mitigating the "vulnerable children crisis". The situation is noted to be complex for children who are living with HIV, whose health needs remain unmet, while communities' capacity to respond effectively is severely constrained. Pettitt, Greifinger, Phelps and Bowsky (2013) state that the clinical, psychological, social, educational, and nutritional needs of children living with HIV remain poorly understood and efforts to mobilise and advocate for their treatment, care and support have been inadequate. As noted earlier, in resource-limited areas of South Africa some of these children living with HIV receive services from drop-in centres. These services include nutritional support through daily meals 
and food parcels, educational support such as homework assistance, and psychosocial support through counselling and referrals to other service providers. SAWs usually oversee the provision of these services in the drop-in centres. It was therefore vital to explore their roles in addressing the biopsychosocial needs of children living with HIV in drop-in centres.

\section{THEORETICAL FRAMEWORK}

The biopsychosocial perspective that stems from the social systems theory Engel, 1980) was used to understand and interpret the philosophical assumptions of this study. The systems theory emphasises the mutual dependence of each system within the whole and suggests that a change in one system will produce changes in the others (Brannon \& Fiest, 1992). This helps one to understand the interaction among the biological, psychological and social components of disease and wellness. Similarly, the biopsychosocial perspective posits that patients' needs can only be understood holistically and addressed adequately if clinicians simultaneously attend to the biological, psychological, and social dimensions of illness (Cohen \& Brown, 2010). The biopsychosocial perspective is thus popular for systematically considering the interdependence and mutual transactions and interactions between biological, psychological and social factors in understanding illness and healthcare delivery (Borrell-Carrió, Suchman \& Epstein, 2004; Germain, 1991; Midgley, 2003).

In the light of the biopsychosocial perspective, modern social auxiliary work practice with clients living with HIV should view every aspect of human life in a holistic manner, and should structure interventions that are sensitive to the multiple systems in which individuals function (Greene, 2000). Children living with HIV live in a social system that functions at various levels: the micro system (individual, group or family), the meso system (children's immediate social network) and the macro system (society on a large scale) (Greene, 2000). It is equally important to note that each systemic level is interdependent with the others and that theoretically none has functional priority over the others (Miller \& Page, 2007). Therefore SAWs should enhance their role and competencies by shifting from linear thinking to holistic thinking that allows understanding of the various complex, but mutually interdependent, and systemic factors affecting children living with HIV. The biopsychosocial perspective provides a holistic conceptual framework that focuses on the interdependent relationship between various factors that underscore the interrelatedness that prevails between children living with HIV and various biological, psychological social processes (Dale, Smith, Chess \& Norlin, 2006; Midgley, 2003).

\section{PROBLEM STATEMENT AND RESEARCH QUESTION}

A major challenge that has been identified in paediatric HIV intervention programmes in South Africa is the "lack of sufficiently trained health care personnel" (Meyers, Moultrie, Naidoo, Cotton, Eley \& Sherman, 2007:474). Thus, in spite of drop-in centres' reliance on SAWs to perform multiple functions in providing care for children living with HIV, SAWs have minimal training relevant to HIV and consequently have sparse paediatric HIV knowledge, skills and experience to improve uptake of HIV care services by children living with HIV (Amzel, Toska, Lovich, Widyono, Patel, Foti, Dziuban, Phelps, Sugandhi, Mark, \& Altschuler, 2013). Pharaoh (2005) also argued similarly that SAWs have fragmented and negligible HIV knowledge and skills, which impacts substantially on their ability to undertake and provide these specialist services to children living with HIV. Consequently, this has an influence on the ability of children living with HIV to access comprehensive, supportive and responsive health services aimed at tackling the complex biopsychosocial needs faced by these children.

Nevertheless, SAWs are the highest category of 'skilled paraprofessional' found in most of the drop-in centres. Despite SAWs being a vital cog in the care of children living with HIV in community-based facilities, their roles and competencies related to addressing the health needs of children living with HIV are not well understood as limited formal studies that have been conducted on the subject. This study's research question was: What are the roles of social auxiliary workers at drop-in centres in addressing the biopsychosocial needs of children living with HIV? 


\section{RESEARCH METHODOLOGY}

\section{Research approach and design}

This research utilised the qualitative research approach. The study applied the case study design to gather "detailed and rich-in-context information" (Fouché \& Schurink, 2011:321) of SAWs' perceptions regarding their role and competencies in addressing the biopsychosocial needs of children living with HIV at drop-in centres. The collective case study design was also used for its popularity in qualitative research as it allows for meaningful interpretation of multiple perspectives in a study (Creswell \& Creswell, 2018).

\section{Research site}

This study was conducted with SAWs working at drop-in centres that are operating in the Sedibeng District Municipality, in Gauteng province. Sedibeng District Municipality consists of three local municipalities, namely Lesedi, Midvaal and Emfuleni. According to Statistics South Africa (2016), the 2011 population of this District was estimated at approximately 957528 . Because of its lower rentals and proximity to Johannesburg, Sedibeng District Municipality is the residence of people who migrate from different places to search for economic opportunities in greater Johannesburg (Statistics South Africa, 2016). In this respect, Sedibeng is host to several social and development challenges, which inversely affects the district municipality's ability to render health services to its residents and vulnerable populations.

\section{Study population and sample}

Purposive sampling was used to select 10 SAWs for the study. Purposive sampling was preferred, since it allowed a sample of "relevant" and "information-rich participants" to be selected (Bryman, 2008:458; Struwig \& Stead, 2001:122). The researchers firstly employed criterion sampling (as part of the purposive sampling technique), which entailed that the researchers decided at the design stage to specify the typical characteristics of participants that were to be included in the study (Nieuwenhuis, 2007). The main typical characteristics of SAWs who were included in the study were that the participants had to be registered with SACSSP, working directly with children who are living with HIV in drop-in centres, having at least a year's experience working in a drop-in centre and were willing to participate in the study.

\section{Data collection and analysis}

A semi-structured one-on-one interview schedule was used as a data-collection instrument to gain a detailed picture of participants' perceptions and experiences of the topic (Greeff, 2011). The semistructured interview schedule consisted of three kinds of questions: main questions, probes and followup open-ended questions that allowed greater interaction between the researchers and the SAWs. Thematic analysis of the transcriptions of the interview recordings was undertaken, leading to the generation of five themes, which are reported on in this article.

Trustworthiness of data was ensured by applying four principles to the qualitative data, namely credibility, dependability, transferability and conformability (Bryman, 2008; Creswell \& Creswell, 2018). Trustworthiness was enhanced through prolonged interview sessions that were punctuated with probing questions until data saturation was reached. The researchers would also read interview transcripts numerous times until they were able to capture accurate descriptions of perceptions and experiences as reported by SAWs. In addition, credibility was ensured through member checking. This entailed interpreting the information and then checking with the participants if the interpretation and thematic analysis were consistent, correct and congruent with their experiences (Greeff, 2011). Besides enhancing credibility, this was also essential in ensuring that information was not subjectively interpreted. Lastly, trustworthiness was ensured by peer debriefing and external audits as the researchers engaged with fellow researchers and other experienced colleagues in reviewing data and their interpretation. This was useful in detecting gaps in the collected data. 


\section{Ethical considerations}

Farrimond (2013) states that successful researchers are those who identify key ethical principles that can impact on their study and incorporate them into their entire research process, from design to data collection and analysis to the publication of findings. Therefore, this study paid due attention to the following ethical issues, namely informed consent, voluntary participation, avoiding deception of participants, confidentiality, privacy, anonymity, avoidance of harm and debriefing of participants. Ethical approval was granted by the University of Pretoria's Research Ethics Committee (Reference No. 14263442 [GW20150805HS]). Permission to conduct the research with SAWs in the drop-in centres was granted by DSD. Lastly, the authors declare that there is no conflict of interests.

\section{FINDINGS AND DISCUSSION}

Ten SAWs working with children living with HIV in drop-in centres participated in the study. This section presents and interprets the qualitative data obtained from the interviews with the participants. The empirical findings of the study are presented in two main parts: first, the biographical information of the participants, and second, the themes from the data that were derived from the interviews. The findings will be corroborated by direct quotes to give voice to the views of the participants $(\mathrm{P})$. The key findings will also be highlighted and substantiated with reference to the relevant literature.

\section{Biographical profiles of participants}

The biographical profiles of the ten participants are displayed in the table below. Their profiles include the following variables: gender, age, years of qualification as a SAW, and years of experience working in a drop-in centre.

TABLE 1

BIOGRAPHICAL PROFILE OF PARTICIPANTS $(\mathbf{N}=10)$

\begin{tabular}{|c|c|c|c|c|}
\hline Participant & Gender & Age (years) & $\begin{array}{c}\text { Years of qualification as } \\
\text { SAW }\end{array}$ & $\begin{array}{c}\text { Years of experience } \\
\text { (drop-in centre) }\end{array}$ \\
\hline 1. & Male & $26-31$ & 3 & 2 \\
\hline 2. & Male & $26-31$ & 6 & 4 \\
\hline 3. & Male & $26-31$ & 6 & 5 \\
\hline 4. & Female & $20-25$ & 3 & 5 \\
\hline 5. & Female & $26-31$ & 5 & 6 \\
\hline 6. & Female & $26-31$ & 6 & 6 \\
\hline 7. & Female & $32-38$ & 7 & 6 \\
\hline 8. & Female & $32-38$ & 7 & 6 \\
\hline 9. & Female & $32-38$ & 7 & 6 \\
\hline 10. & Female & $32-38$ & 7 & 5 \\
\hline
\end{tabular}

The table above indicates that, out of the 10 participants, 7 were female and 3 were male. This was expected, because females currently dominate the social welfare sector (Fischl, 2013). Men typically consider social welfare professions, such as social auxiliary work, to be feminine occupations as much of the work entails addressing insecurities and hidden issues, which contradicts the backgrounds of many men, who were taught in growing up to mask their emotions and discouraged from talking about their feelings and insecurities (Fischl, 2013). The lack of participants over the age of 38 years may be because SAWs in this age group are more likely to have branched to occupying more senior and/or different roles in government departments or other related social welfare sectors. In the context of years of employment in a drop-in centre, 5 of the participants had been employed for 6 years; whilst 2 participants had been employed for 5 years; 2 had been employed for 2 years, and there was only 1 participant who had been 
employed for 4 years. The researchers explain this on the basis that one of the criteria for participant selection was that participants had to have been employed for at least one year in a drop-in centre.

\section{Themes and sub-themes}

The main themes and sub-themes which were identified during data analysis are presented and discussed in this sub-section. They are first presented in a table then explained in detail. These themes and subthemes focused on the biopsychosocial needs of children living with HIV and the impact they have on the wellbeing of the children if they are unmet. Some of the main themes also focused on the roles, knowledge and skills of SAWs, their experiences and perceived effectiveness and challenges in addressing the biopsychosocial needs of children living with HIV as well as the strategies and changes required to effectively support children living with HIV in drop-in centres.

\begin{tabular}{|l|l|}
\hline Themes & Sub-themes \\
\hline $\begin{array}{l}\text { Theme 1 } \\
\text { Bio-medical needs of children living with HIV }\end{array}$ & $\begin{array}{l}\text { Limited access to medication. } \\
\text { Poor nutrition. } \\
\text { Opportunistic infections. }\end{array}$ \\
\hline $\begin{array}{l}\text { Theme 2 } \\
\text { Psychological needs of children living with HIV }\end{array}$ & $\begin{array}{l}\text { Mental health, anxiety and depression. } \\
\text { Stigma and discrimination. } \\
\text { Education and schooling needs. }\end{array}$ \\
\hline $\begin{array}{l}\text { Social needs of children living with HIV } \\
\text { Theme } \mathbf{4}\end{array}$ & Poverty and unmet material needs. \\
\hline $\begin{array}{l}\text { Theme 5 } \\
\text { Roles and competencies of social auxiliary } \\
\text { workers at drop-in centres }\end{array}$ & $\begin{array}{l}\text { Preventive interventions to contribute to the maintenance of } \\
\text { health and the prevention of diseases. } \\
\text { Psychosocial care and support. } \\
\text { Provision of meals and material needs. } \\
\text { Facilitating referral of clients to resource systems. }\end{array}$ \\
\hline
\end{tabular}

\section{Theme 1: Bio-medical needs of children living with HIV}

From the participants' responses with regards to the bio-medical needs of children living with HIV, three main sub-themes emerged from this theme, namely limited access to medication, poor nutrition, and susceptibility to other diseases (opportunistic infections).

\section{Sub-theme 1.1: Limited access to medication}

All the participants indicated that the communities they live in are not geared towards the 'inclusion' and 'integration' of children living with HIV, which consequently creates barriers for children to access ARVs and related care and support medical services. The following comments indicate the sentiments of the participants regarding this matter:

Most such children that I suspect are HIV positive are not on treatment because they have not been tested. Some of them their parents have died from the disease. (P1)

Because children lack information on their status, it is not even possible for them to know where to start in seeking for medical attention, and the parents of these children are not cooperative with us when we seek to intervene as they would not have disclosed to the children. (P8)

Such responses have also been shared by many authors such as Meyers et al. (2007:476), who have asserted that there are many children in South Africa who are infected with HIV but are not receiving ART and are not entering HIV care and support services because of "no or late diagnosis". This might be due to lack of knowledge and cooperation by some parents and guardians of children living with HIV, who consequently fail to be identified and referred to appropriate services. The responses reflect the findings from a multi-centre cohort study in South Africa by Fatti, Shaikh, Eley and Grimwood (2014:02) which showed that home visits by lay "patient advocates", such as SAWs, to the households of children living with HIV did not produce any positive outcomes in instances where parents chose not to co- 
operate. These findings confirm the global picture that has been shared by the United Nations Programme on HIV/AIDS (UNAIDS) (2013) and the United Nations International Children's Emergency Fund (UNICEF 2013) that, for various reasons, many children who are HIV positive are not accessing treatment, resulting in a treatment gap where 1.9 million children globally qualify for HIV drug treatment, but only 650,000 are receiving it. An important aspect to note in the access to appropriate medical care is the reluctance of parents to disclose the HIV status to their children, as mentioned by Participant 8 . This presents a unique aspect of this finding that also needs to be addressed (see sub-theme 3.1).

\section{Sub-theme 1.2: Poor nutrition}

Most participants pointed out that children living with HIV struggled with accessing adequate nutrition, which is best achieved through consumption of a balanced healthy diet. The participants explained that in most instances the growth and development of children living with HIV was very poor as their nutritional requirements were not being met. Participants described these situations as follows:

Children with HIV do not eat well, and their growth is very poor, especially here in Sedibeng where the socioeconomic circumstance of many parents is terrible due to unemployment. (P3)

Lack of nutritious food for children with HIV is very common in our community because of poverty. (P7)

These responses support findings from a study done in Uganda and Zambia by Rawat, Kadiyala and McNamara (2010) to establish the impact of overlap between HIV prevalence and malnutrition in poor communities. The study noted that many children living with HIV are orphaned and/or live in poverty, which makes them more prone to malnutrition. Furthermore, the study established that food insufficiency and hunger generally worsen health outcomes for children living with HIV and drive non-adherence amongst those who might be on treatment. It is clear from the above findings that participants view nutrition as playing a decisive role in the overall health and wellbeing of children living with HIV. The relevance of the interplay between HIV, poverty and nutrition that was cited by participants is explained by the World Health Organisation (WHO) (2009:7) as being very common in "resource-poor settings and a major contributor to growth faltering among HIV-infected children". The World Health Organisation (WHO) (2009) emphasises the important relationship between HIV, nutrition, growth and survival of children living with HIV and recommends that nutritional assessment and support should be an integral part of the care plan of an HIV-infected child.

\section{Sub-theme 1.3: Opportunistic infections}

Participants indicated that children living with HIV suffer from opportunistic infections that occur because of being infected with HIV. The participants described the situation as follows:

Infected children are at risk of easily contracting other illnesses such as flu, tuberculosis, and coughing ... (P4)

...one of our children always suffered from one disease to another before we knew she was HIV positive. At one time she was diagnosed with tuberculosis; it was not good at all. (P10)

The above excerpts are in tandem with the assertions of De Schacht, Lucas, Mboa, Gill, Macasse, Dimande, Bobrow and Guay (2014), who alluded to the fact that children living with HIV are prone to other medical conditions such as pneumonia and tuberculosis, especially if they are not on treatment. In some instances, opportunistic diseases are the earliest and most devastating markers of infection in children (Vranda \& Mothi, 2013). It can also be added that the responses are in line with the submission made by Pettitt et al. (2013) that children who were born with HIV and are not on treatment are more likely to be in advanced stages of the illness, with a history of opportunistic infections and viral resistance laced with other comorbidities, making their treatment more complex, even when they are finally put on ART. 


\section{Theme 2: Psychological needs of children living with HIV}

Participants confirmed that HIV poses a direct threat to the psychological health, functioning and wellbeing of children living with HIV, particularly given the burden of stigma, poverty and stressors related to consequences of living with HIV.

\section{Sub-theme 2.1: Mental health, anxiety and depression}

Participants indicated that it seems common for children who are living with HIV to experience mental, emotional, anxiety and depression challenges that are a result of the struggles they go through in their lives. Participants also mentioned that the mental health challenges that children face are directly related to the social determinants of health (such as stigma, poverty, and orphanhood) and psychosocial stressors related to living with HIV. One participant mentioned the following:

The three children that l know to be HIV positive in our drop-in centre do not listen or pay attention to details when we are having our activities. They always look distracted and they are very sad and distant; it is as if they have some mental problems. (P8)

Another participant explained that she learnt about most of the mental health problems of the child through the class teacher, who expressed a concern that

The child was emotional and expressed many behavioural problems and was always anxious and socially withdrawn from other children in her class. (P3)

The above experiences and opinions highlight the concern of participants regarding the socio-emotional wellbeing of the children in their care. Their opinions are in line with the observations of an HIV and Child Mental Health Case Control Study that was done in Rwanda by Betancourt, Scorza, Kanyanganzi, Fawzi, Sezibera, Cyamatare, Beardslee, Stulac, Bizimana, Stevenson and Kayiteshonga (2014:467) which concluded that "HIV-positive children have higher levels of depression, mental disorders, anxiety, conduct problems, and functional impairment compared with HIV-unaffected children". Findings from a study by Lowenthal, Bakeera-Kitaka, Marukutira, Chapman, Goldrath and Ferrand (2014) that reviewed challenges facing adolescents from Sub-Saharan Africa with perinatally acquired HIV infection corroborate the responses, as they established that, besides dealing with the chronic illness, the adolescents had to confront psychosocial issues, while undergoing rapid physical and psychological development.

\section{Theme 3: Social needs of children living with HIV}

The participants recognised that most of the social problems faced by children living with HIV are exacerbated by the fact that parents and families are not doing well enough when it comes to disclosing HIV diagnosis to children; this in turn creates the grounds for stigma and discrimination against children living with HIV. Participants also viewed HIV as having a negative impact on children's educational and schooling activities.

\section{Sub-theme 3.1: Non-disclosure by parents}

All participants cited challenges of non-disclosure of children's HIV positive status to them by parents as the most difficult challenge that the children have to endure. Non-disclosure impacts not only on children's understanding of their HIV status, but on their access to health services and adherence to medication for those children that might be on ART. Some of the responses from participants are as follows:

Parents do not tell their children that they have HIV, and this makes it difficult for us and other community members to help the children to deal with their status. (P2)

There are lots of misconceptions about HIV on the part of parents and caregivers, which lead to secrecy and non-disclosure, which in turn puts infected children at risk of not being able to access treatment. (P5) 
Participants highlight vital factors such as secrecy and the socio-emotional consequences for all. These responses fit well with the findings of Chikwari, Simms, Busza, Dauya, Bandason, Chonzi, Munyati, Mujuru and Ferrand (2018) from an evaluation of community support programmes to improve HIV treatment outcomes for children and adolescents in Zimbabwe. The study established that refusal of HIV disclosure to children by parents creates multiple barriers, including obstruction of access and adherence to ART, and understanding at an early age of the impact of sexual activity on the spread of HIV. The responses indicated above are also confirmed by Bikaako-Kajura, Luyirika, Parcell, Downing, Kaharuza, Mermin, Malamba and Bunnell (2006), who conducted a study that sought to assess issues of HIV disclosure and ART adherence among HIV-infected children in Uganda. The study revealed that lack of disclosure creates intrapersonal conflict as it does not allow for open conversations about living with HIV between parent and child, thereby blocking avenues for children to access medication and social support. As mentioned by some participants above, not discussing HIV and disclosing a child's positive status can create a context of secrecy, mistrust and confusion, and this puts the child at risk of negative health outcomes (Rwemisisi, Wolff, Coutinho, Grosskurth \& Whitworth, 2008). Besides bio-medical consequences for those children that might be on ART, some of the adverse outcomes of non-disclosure that parents might need to contend with include decreased trust between child and parent, and feelings of fear, anxiety and resentment towards the parent by the child as well as about the medication (BikaakoKajura et al., 2006).

\section{Sub-theme 3.2: Stigma and discrimination}

There were an overwhelming number of participants who cited stigma and discrimination as a significant obstacle that children living with HIV encounter in their daily lives. The seriousness of stigma, isolation and discrimination against children living with HIV are summarised in the following comments:

In our community, some community members do not want their children to mix with children suspected of having HIV ... they even tell their children not to play with those children. (P7)

Discrimination is a reality for children that have HIV especially in schools where teachers and other pupils do not know how to relate to them. (P9)

The responses in this study confirm views that have been shared by numerous authors that children living with HIV often experience stigma and isolation, and are ostracised by their communities (and in some instances by close relatives), who are supposed to protect them (Campbell, Foulis, Maimane \& Sibiya, 2005). The fact that some community members do not want their children to mix with children suspected of having HIV illustrates not only that there is still much inaccurate information about how HIV is transmitted, but also that HIV is perceived to be a life-threatening disease. The responses are supportive of conclusions from a multi-country study that was done by Pettitt et al. (2013) to assess ways of improving health services for adolescents living with HIV in Sub-Saharan Africa. The study found that stigma and discrimination are "twin evils in severely limiting most forms of social support" mostly related to the lack of communication in some sections of society. Muchanyerei (2016) shares similar views and adds that the negative experiences, mostly related to the lack of communication, affect healthseeking behaviour by children and adolescents living with HIV. Campbell, Andersen, Mutsikiwa, Madanhire, Nyamukapa and Gregson (2016:01) remark that the degree of exclusion, fear and exhaustion that children living with HIV suffer due to stigma and discrimination is extreme - "only the literature on the holocaust comes close to matching it".

\section{Sub-theme 3.3: Education and schooling needs}

The participants commented that children living with HIV are faced with challenges such as absenteeism from school, school dropout, illness, and stigmatisation. Participants also noted that, not only do children living with HIV have to battle with illnesses related to their status, but they also performed poorly in school because their teachers are not knowledgeable on how to assist them. The following are some of the responses: 
Schools lack support systems. For example, teachers at school do not know how to handle or support children that are living with HIV. (P5)

Children infected by HIV miss many days of schooling due to illness. (P6)

Such responses from most of the participants indicate that HIV is viewed as a factor that hinders children from effectively accessing and participating in educational and other schooling activities.

The responses confirm findings by Gicharu, Mwaniki, Kibui, Gichuhi and Kahiga (2015) which emerged from a study in Kenya that investigated the effects of HIV and AIDS on the academic performance of children. Their findings indicated that there was an increase in the number of pupils dropping out of school and a decline in school attendance due to various HIV-related difficulties that impacted on infected children such as personal illness, discrimination, stigma and declining financial support from parents. Gicharu et al. (2015:19) also affirm that "lack of essential learning resources and conscientized teachers" in poor settings contribute to poor performance of pupils infected by HIV and overall "put a strain on their educational rights". Similar conclusions were arrived at in a study conducted by Campbell et al. (2016) with Zimbabwean teachers to explore how schools can support HIV/AIDS-affected children. The study established that children living with HIV seldom received support from their teachers because of multiple factors such as the inability of teachers to solve HIV/AIDS-related problems in their own lives; they lack the skills and capacity to support affected pupils; and their inability to manage the role of stigma in deterring HIV/AIDS-affected children from disclosing their situations to teachers. Campbell et al. (2016) observed that not only did these factors undermine caring teacher-pupil relationships, but they also stifled the confidence and motivation of children living with HIV to thrive in school.

\section{Theme 4: Economic needs of children living with HIV}

Participants mentioned that most children living with HIV in their community come from very impoverished households where financial difficulties are experienced daily. Participants viewed poverty as having a potentially detrimental effect on the provision of material needs essential for the treatment and care of children living with HIV.

\section{Sub-theme 4.1: Poverty and unmet material needs}

Poverty was also seen as a key challenge that inhibits children living with HIV from meeting their basic physiological needs as well as impacting on their economic wellbeing. Six participants noted that most children living with HIV in their communities tend to come from poorer households where their parents and guardians are not employed. The following responses from the participants indicate how poverty reinforces and aggravates many of the vulnerabilities that children living with HIV encounter in their lives:

There is very high unemployment in our community, which makes it easy for children in our communities to experience hunger daily and suffer from malnutrition. (P1)

Some of the parents of HIV-positive children are themselves ill and they cannot work to provide food and clothing to their children. (P9)

Here in Sedibeng many families live in poverty and they cannot afford adequate food for their children. Unfortunately, those children that are on antiretroviral treatment should eat a lot of food, food that is not available in their homes. (P10)

The responses are in line with observations that have been made by various researchers that poverty exacerbates the poor socioeconomic situation of children living with HIV by weakening their potential social and economic support systems. The fact that more than half of the participants in this study cited poverty to be a major threat to the health and wellbeing of children living with HIV supports the assertion by Mokgatle and Madiba (2015) that most children who are infected by HIV in South Africa are from provinces and districts that are characterised by unemployment and poverty. "Poverty, unemployment and underemployment" in households can result in children living with HIV experiencing poor levels of 
nutrition, food insecurity and malnutrition (Mokgatle \& Madiba., 2015:4). Compared to employed parents, unemployed parents cannot provide the basic needs such as health care, basic food, clothing, shelter and the education needed for the good health and development of their children (Hall, 2012).

In addition, the responses are comparable to those that are shared by Niang and Van-Ufford (2002) from their study in Senegal on the impact of socio-economic factors on children affected by HIV/AID. The study found that poverty exposed HIV/AIDS-affected children to precarious situations as it induced considerable instability in their lives by decimating their nuclear families leading to the children living with other relatives. Niang and Van-Ufford (2002) add that the destruction of family and social networks led to some of the children living under unstable and progressively deteriorating living conditions, which in the long run appeared to have a strong impact on self-perception, emotional stability, and the construction of individual and family identities for the children.

\section{Theme 5: Roles of social auxiliary workers at drop-in centres}

From the participants' responses with regards to their roles, the researchers identified several roles that characterise the work of SAWs working with children living with HIV at drop-in centres. These roles include: preventive interventions to contribute to the maintenance of health and the prevention of diseases, psychosocial care and support, provision of meals and material needs, life skills development, and facilitating referral of clients to resource systems.

\section{Sub-theme 5.1: Preventive interventions to contribute to the maintenance of health and the prevention of diseases}

Most participants acknowledged that, when it comes to children living with HIV, they had a 'preventive' role to contribute to the maintenance of health and the prevention of diseases in the lives of children. The SAWs described their 'preventive' role in various ways, but all of them seemed to suggest that they were related to treatment adherence and access to health services support activities that were meant to prevent children known to be living with HIV from sliding further into attack or infection by other diseases by ensuring they adhere to their medication. The following participants' views capture this sub-theme as follows:

For the two children that are HIV positive that l work with, I make sure I do regular home visits to check if the children are taking their medication so that they stay strong and do not get attacked by other opportunistic diseases. (P2)

I help HIV-infected children by doing health monitoring of their adherence, especially those children that are living with grannies. (P4)

My role includes following up with the family to take the children for scheduled check-ups at the clinic. (P8)

The responses indicate that, in cases were SAWs know the status of children and there is open communication with the parents or guardians of the children, supportive home visits are done to ensure the children are taking their medication and keeping their clinic appointments. Participants' responses are supported by Jamieson and Berry (2012), who state that preventive interventions conducted by dropin centres should be undertaken in the context of the South Africa's Primary Health Care Policy (Department of Health, 1997), which states that the services of drop-in centre staff should be to strengthen health outcomes for children living with HIV by ensuring they have access to health, counselling, treatment and rehabilitation services. The responses confirm findings from a systematic review of the literature on community health programmes undertaken by Scott, Beckham, Gross, Pariyo, Rao, Cometto and Perryet (2018) which established that the integration of SAWs into community health systems was crucial in embedding and bolstering the sustainability and credibility of programmes for children living with HIV. It can also be noted that the responses underscore the recommendation made by the World Health Organisation (WHO) (2018) that the use of lay workers in community settings reduces costs and increases uptake of HIV testing services for children, adolescents, and young adults. 
On being asked their opinion on how effective they were in their preventive role, the SAWs had the following to say:

Our support services to HIV-infected children only work when their families are welcoming to us; unfortunately some family members do not want to welcome us in their homes due to stigma issues and we cannot force ourselves on them. (P4)

It is a struggle to support children living with HIV since most of them do not know that they have HIV as their parents have not told them, and we do not know how to handle such situations.

The responses show that effectiveness of SAWs in providing supportive and "preventive" health services to children living with HIV are constrained by the reluctance of some parents to disclose the condition to the children and refusing to have the SAWs visit the children. This is in contradiction to the Children's Act, Section 144(1), which prescribes that prevention and early intervention programmes should be aimed at strengthening and supporting families with children in difficult circumstances so that problems can be prevented from escalating (Jamieson \& Berry, 2012). Participants noted that, as SAWs, they did not think they have the skills to deal with most parents who are overly protective and resist disclosure to their children, a situation that makes it impossible for them to support children living with HIV. These narratives provide insights into circumstances that impact on the ability of SAWs to render good quality care to children living with HIV.

The narratives are supported by findings from studies by Casale,_Carlqvist and Cluver (2019), who noted that there was "scarce and inconclusive evidence of effective" training and skilling of community cadres, such as SAWs, to implement multifaceted interventions aimed at addressing broader social barriers to treatment, adherence and retention for children living with HIV. The authors call for urgent action to design, implement and test effective and scalable interventions that upskill community cadres. Pettitt et al. (2013) corroborate the responses above by remarking that little guidance has been produced on how to effectively capacitate community cadres and that which does exist lacks a primary focus on children living with HIV.

Preventive work for HIV is often associated with capacitating children with various life skills. Consequently, three participants stated that their work with children living with HIV involved building their life skills (life skills development). The views of one participant in this regard are captured as follows:

Our life skills development activities are done during homework support; we teach children to speak and to be confident in what they do. (P7)

The responses show that "life skills development" as a concept is overly simplified by participants, who tended to view the homework assistance services that they give to children as being synonymous with life skills development. The oversimplification of the concept of life skills development by participants is evident when one takes into account the definitions of life skill that are given by the WHO as well as the Department of Social Development (DSD, 2013:36) specifies that "life skills development is based on empowering children by harnessing their own strengths, abilities, beliefs, accomplishments, values, interests, and resources to deal effectively with the demands and challenges of every day". Examples of a core set of life skills that are at the heart of skills-based development initiatives for the promotion of health and well-being for children, include problem solving, critical thinking, and communication, collaboration and cooperation skills (WHO, 2010:2). As already noted above, the responses from study participants are indicative of the lack of training leading to a disconnect between the services that SAWs provide and what DSD expects them to provide. 


\section{Sub-theme 5.2: Psychosocial care and support}

All participants pointed out that they render psychosocial care and support programmes to address the needs of children living with HIV. The activities of what constitutes psychosocial care and support roles differed amongst participants. The following comments demonstrate this:

We offer emotional, spiritual and social support by doing home visits to the homes of children infected by HIV. (P2)

By talking and listening to the concerns of HIV positive children, it can be said we are supporting them psychologically as well as emotionally. (P3)

Children come to our centre to eat cooked food and get food parcels, and this is an important element of fulfilling our psychosocial care and support role as a drop-in centre. (P8)

I do counselling with HIV-positive children as part of our psychosocial care and support programmes. We also give them food parcels and clothes and school material that we get as donations from supermarkets. (P10)

The responses above indicate that the definition and understanding of psychosocial care and support amongst SAWs working with children living with HIV in drop-in centres is varied and individualised. Participants cited giving cooked meals and food parcels, doing home visits, assisting with school homework, offering clothes and other material assistance, as well as 'talking' to children as key activities that, when provided either individually or collectively, comprise psychosocial care and support. The fact that there is not one clear uniform and objective view of what psychosocial care and support entail amongst the participants shows the 'social complexity' that is also attached to measuring the effectiveness (competencies) of SAWs rendering psychosocial services in drop-in centres as views were different depending on one's own experience and meaning. These responses underscore the views of Yeap, Hamilton, Charalambous, Dwadwab, Churchyard, Geisslera and Granta (2010:1105), who note that, as much as there is a desire amongst drop-in centres to holistically structure and implement multiinitiatives that address the dynamic social complexities affecting children, the lack of boundaries and a common definition of "psychosocial care and support" obfuscates the services landscape for caregiving staff, who would not know what to focus on, and how to measure their effectiveness (competency) in identified aspects.

The account above is supported by the Regional Psychosocial Support Initiative (REPSSI), a nongovernmental organisation well known for promoting psychosocial care and support activities for children affected by HIV and AIDS in Southern Africa. REPSSI (2016:37) reports that in their work with drop-in centres in South Africa, they found SAWs and other community care workers to be unsure about how to help children to deal with the practical and emotional issues deriving from being infected and affected by HIV and AIDS as "a lot of the issues that often come up were not covered in their training" REPSSI (2016). Psychosocial care and support (PSS) include many different aspects of life, including physical and material aspects, psychological, social, cultural and spiritual aspects. REPSSI (2016) therefore encourages SAWs to be capacitated to appreciate the connectedness and interdependence between the individuals (children living with HIV) and their households, families and communities.

\section{Sub-theme 5.3: Provision of meals and material needs}

Participants noted that chief amongst their roles was to fulfil DSD expectations that drop-in centres are to provide meals, food parcels, clothing, scholastic and other material items to all needy children who come to the centres. Participants mentioned the following:

As part of nutritional support, I make sure all children receive cooked meals. (P1)

We provide some material support in the form of school uniforms, shoes and writing exercise books in the case where families cannot afford. (P6) 
The above responses are vital in illustrating the importance of roles that are played by macro-systems in the creation of circumstances or environments that either aid or hinder the addressing of the needs of children living with HIV. Although participants appreciated the support from DSD, other participants asserted that:

The funding that the drop-in centres was getting from government through DSD was not sufficient to address food and material requirements of all children living with HIV. (P5)

These sentiments are supported by remarks made by Budlender and Proudlock (2011) that the subsidies provided by DSD to drop-in centres and NGOs do not cover the full cost or scope of the social welfare services that need to be rendered and this seems to be the biggest hurdle in proper service delivery.

Pettitt et al. (2013) confirm the complex and bidirectional relations between nutrition and HIV by noting that chronic malnutrition is a pervasive problem amongst children living with HIV as there is rarely enough food to meet their needs as a result of the shortage of funding for care programmes. Pettitt et al. (2013) further report that taking medication on an empty stomach can greatly affect adherence and may prompt children living with HIV to stop taking their medications completely when they do not have enough food to eat. The authors encourage governments to adequately fund HIV programmes to avoid nutrition-related complications amongst children living with HIV, particularly in resource-poor environments.

\section{Sub-theme 5.4: Facilitating referral of clients to resource systems}

Most participants mentioned that facilitating referral of children living with HIV to resource systems was a major role that was expected of them. The participants mentioned the following:

HIV positive children, like other children, have many needs so we refer them to psychologists, Home Affairs, SAPS (South African Police), clinics, and SASSA (South Africa Social Security Agency). These services are very far away from our community, so many children and families that we refer do not go as they do not have transport fare. (P1)

We network with other CBOs for things like food and referrals ... We have churches, supermarkets and private sponsors that help us with the funding when we refer our children. (P10)

From the responses it is clear that by virtue of the nature of their profession and the type and limited resources that are found in drop-in centres, SAWs are not able to meet all the needs of children, hence they have to do referrals. This is in line with the requirements of the Social Service Professions Act, 1978 (Act 110 of 1978), which specifies that social auxiliary work is a supporting service, which includes facilitating referrals to resource systems, a role which involves informing, educating and enabling clients to access and utilise resources. The narratives above are in line with assertions made by Fatti et al. (2014) that children living with HIV have a myriad of needs and challenges that cannot be met by one service provider, but rather by cross-programme collaborations through referrals. Budlender and Proudlock (2011) specifically point out that drop-in centres would potentially benefit from referring children living with HIV to other specialised care agencies, such as clinical psychologists or psychiatrists, as SAWs are not equipped or qualified to offer these specialised services.

\section{CONCLUSIONS}

The following conclusions were derived from the findings of the study.

- Children living with HIV have many distinct bio-medical, psychological and social needs that impact on their wellbeing. The study therefore concludes that the biopsychosocial approach should be adopted to allow for comprehensive, integrated, inclusive, multi-sectoral and high-quality HIV treatment, care and social support programmes for children living with HIV to be sustainably and holistically implemented. Presently there are no mechanisms, activities or programmes aimed at identifying children living with HIV in drop-in centres, an aspect which complicates the integration 
of the biopsychosocial needs of children living with HIV into other services rendered in drop-in centres.

- SAWs are not effective in their roles; especially targeted at addressing the biopsychosocial needs of children living with HIV, because they do not have any specific training on working with children living with HIV.

- By virtue of being based in the communities, drop-in centres and SAWs have the potential to do more as far as addressing the unique needs of children living with HIV is concerned.

- There are no mechanisms, activities or programmes aimed at identifying children living with HIV in drop-in centres, an aspect which complicates the integration of the biopsychosocial needs of children living with HIV into other services rendered in drop-in centres. SAWs particularly struggle to work with children living with HIV who will be transitioning into adolescence. This is exacerbated by limited and irregular supervision being rendered to SAWs by the DSD. This aspect deprives the SAWs of guidance and debriefing opportunities.

- Stigma and discrimination within communities prevent many parents and guardians from disclosing their HIV status to their children. Non-disclosure of positive HIV status to children by parents and guardians isolates children living with HIV and acts as a barrier for the children to access appropriate treatment, care and other social support services.

- The funding that drop-in centres receive from government through DSD is inadequate for SAWs to sufficiently address the biopsychosocial needs of children living with HIV. As concluded in this study, some of the biopsychosocial needs of children living with HIV are material in nature as a result of the poverty and unemployment of their parents. The study therefore concludes that DSD should consider increasing funding for drop-in centres as this will enable social auxiliary workers to provide for the biopsychosocial needs of children who require financial or material resources.

\section{RECOMMENDATIONS}

The findings of this study confirm the challenges that SAWs encounter in working with children living with HIV in drop-in centres. The challenges affect the roles and competencies of SAWs. Based on the key findings and conclusions of the study, a number of recommendations are made.

\section{Training of SAWs on paediatric HIV and the biopsychosocial approach}

Training institutions must train SAWs on paediatric HIV to address their insufficient knowledge and skills. Drop-in centres can also capacitate SAWs through in-service training. Findings indicate that limited knowledge, skills and experience that SAWs have of paediatric HIV significantly lowers the effectiveness of their work. Thus, the training and capacitation of SAWs in paediatric HIV could contribute to an increase in the depth and breadth of HIV services that children living with HIV will ultimately receive. The researchers also suggest that, besides making SAWs more effective by upgrading their HIV knowledge, providing skills training on paediatric HIV could enable the SAWs to understand and appreciate the emotional difficulties involved with working with children living with HIV. In addition, there is a need to educate SAWs in the practical application of a biopsychosocial approach in rendering services to children living with HIV. This would ensure that SAWs understand the interconnectedness of the biomedical, psychological and social needs of children living with HIV and they are able to address them in an organised and integrated manner.

\section{Provision of simplified and standardised intervention services}

Stakeholders such as training institutions and the DSD should provide SAWs with simplified and standardised intervention services that they can use in their daily work with children living with HIV. This would solve most problems that SAWs encounter in understanding, interpreting and applying HIV policy and legislative frameworks in the context of their work with children living with HIV. The study findings revealed that there is no uniform understanding of roles such as counselling and psychosocial 
care and support. Thus, the provision of simplified practice tools will ensure that there is consistent understanding amongst SAWs of their roles and obligations. Moreover, this would increase the uniformity, comprehensiveness and efficiency of services rendered to with children living with HIV by SAWs.

\section{Strengthened supervision of SAWs}

There is need to strengthen and re-structure the current supervision models and opportunities that are accorded to SAWs to promote optimal performance and improve standards of service provision to children living with HIV by SAWs. It was noted in the study that some of the cases that SAWs are confronted with are complex and beyond the scope of what they can deal with. Regular, on-going and on-site supervision from skilled social workers could be vital in guiding and increasing the experiences of SAWs in working with children living with HIV. The researchers recognise that frequent supervision sessions could also be essential in providing debriefing opportunities as working with children living with HIV can be a heavy burden that may lead to stress, depression and isolation. Another reason that was cited in the study as contributing to weakened supervision systems for SAWs is the shortage of social workers employed by the DSD. The DSD thus needs to employ more social workers to strengthen the supervision of SAWs and to achieve the SACSSP's recommendations that SAWs should work under the supervision of a social worker.

\section{Scaling up community mobilisation interventions to address HIV stigma and discrimination}

Identifying and addressing HIV-related stigma and discrimination in communities is of paramount importance if children living with HIV are to receive services that meet all their needs. Children living with HIV are not known to SAWs as their parents and guardians prefer to keep both their HIV-positive status and that of their children secret for fear of stigma and discrimination from fellow community members. Community sensitisation and education programmes targeted at HIV-related stigma and discrimination will therefore be vital in demystifying stigma and neutralising discrimination, and this could help in addressing other factors, such as non-disclosure, which disenfranchise children living with HIV from accessing services.

\section{Increasing funding for drop-in-centres}

The available financial and material resources that are allocated to drop-in centres by DSD are not in proportion to the growing needs of children living with HIV, which consequently constrains the quality of services given to the children. There is therefore a need for government and the DSD to consider increasing funding to ensure that SAWs in drop-in centres can sustain their responses and improve the quality of services that they render to children living with HIV. Another recommendation is that the DSD should facilitating linkages to other potential funding institutions or donors.

\section{Further research}

Further research is needed to develop strategies and programme activities that promote the identification, integration and inclusion of children living with HIV into treatment, care and other social support services.

\section{REFERENCES}

AMZEL, A., TOSKA, E., LOVICH, R., WIDYONO, M., PATEL, T., FOTI, C., DZIUBAN, E.J., PHELPS, B., SUGANDHI, N., MARK, D., \& ALTSCHULER, J. 2013. Promoting a Combination Approach to Paediatric HIV Psychosocial Support. AIDS Journal, 27(2):147- 157.

AUGUSTO, G.F. 2012. Treatment of HIV infection: Are we failing the children? Lancet Infectious Diseases, 12(9):664-53.

BETANCOURT, T., SCORZA, P., KANYANGANZI, F., FAWZI, M.C.S., SEZIBERA, V., CYAMATARE, F., BEARDSLEE, W., STULAC, S., BIZIMANA, J.I., STEVENSON, A., \& 
KAYITESHONGA, Y. 2014. HIV and Child Mental Health: A Case-Control Study in Rwanda. Paediatrics, 34(2):464-945.

BIKAAKO-KAJURA, W., LUYIRIKA, E., PARCELL，D., DOWNING, J., KAHARUZA, F., MERMIN, J., MALAMBA, S., \& BUNNELL, R. 2006. Disclosure of HIV status and adherence to daily drug regimens among HIV-infected children in Uganda. AIDS and Behavior, 10(S1):85-93.

BORRELL-CARRIÓ, F., SUCHMAN, A.L. \& EPSTEIN, R.M. 2004. The biopsychosocial model 25 years later: Principles, practice, and scientific inquiry. New York: Rochester School of Medicine.

BRANNON, R. \& FEIST, S. 1992. Theories of personality. $3^{\text {rd }}$ ed. Fort Worth: Harcourt Brace College. BRYMAN, A. 2008. Social research methods. $3^{\text {rd }}$ ed. Oxford: Oxford University Press.

BUDLENDER, D. \& PROUDLOCK, P. 2011. Funding the Children's Act: Assessing the adequacy of the 2011/12 budgets of the provincial departments of social development. Cape Town: Children's Institute, University of Cape Town.

CAMPBELL, C., FOULIS, C., MAIMANE, S., \& SIBIYA, Z. 2005. "I have an evil child at my house": Stigma and HIV/AIDS management in a South African community. American Journal of Public Health, 95(5):808-815.

CAMPBELl, C., ANDERSEN, L., MUTSIKIWA, A., MADANHIRE, C., NYAMUKAPA, C. \& GREGSON, S. 2016. Can schools support HIV/AIDS-affected children? Exploring the 'Ethic of Care' amongst rural Zimbabwean teachers. PLoS ONE, 11(1): 01-22.

CASALE, M., CARLQVIST, A. \& CLUVER, L. 2019. Recent interventions to improve retention in HIV care and adherence to antiretroviral treatment among adolescents and youth: a systematic review. AIDS Patient Care STDS, 33(6): 237-252.

CHIKWARI, C.D., SIMMS, V., BUSZA, J., DAUYA, E., BANDASON, T., CHONZI, P., MUNYATI, S., MUJURU, H. \& FERRAND, R.A. 2018. Community health worker support to improve HIV treatment outcomes for older children and adolescents in Zimbabwe: A process evaluation of the ZENITH trial. Implementation Science, 13(70):02-09.

COHEN, J. \& BROWN, C.S. 2010. John Romano and George Engel: Their lives and work. New York: University of Rochester Press.

CRESWELL, W. J. \& CRESWELL, J.D. 2018. Research design: Qualitative, quantitative and mixed methods approaches. $5^{\text {th }}$ ed. London: Sage Publications Ltd.

DALE, O., SMITH, R., CHESS, W. A., \& NORLIN, J. M. 2006. Human behaviour in the social environment: A social systems model. Boston: Allyn \& Bacon.

DE JAGER, E. 2011. Foster care of AIDS orphans: Social workers' perspectives. Stellenbosch: University of Stellenbosch. (MSW dissertation)

DEPARTMENT OF SOCIAL DEVELOPMENT (DSD). 2005. Guidelines for establishment of community-based multipurpose/drop-in-centres. Pretoria: Government Printers.

DEPARTMENT OF SOCIAL DEVELOPMENT (DSD). 2013. Norms and standards for home and community-based care programmes. Pretoria: Government Printers.

DE SCHACHT, C.D., LUCAS, C., MBOA, C., GILL, M., MACASSE, M., DIMANDE, S.A., BOBROW, E.A., \& GUAY, L. 2014. Access to HIV prevention and care for HIV-exposed and HIVinfected children: A qualitative study in rural and urban Mozambique. BMC Public Health, 14:01-40.

ENGEL, G.L. 1980. The clinical application of the bio-psychosocial model. American Journal of Psychiatry, 137:535-544.

FARRIMOND, H. 2013. Doing ethical research. New York: Palgrave Macmillan. 
FATTI, G., SHAIKH, N., ELEY, B. \& GRIMWOOD, A. 2014. Improved virological suppression in children on antiretroviral treatment receiving community-based adherence support: A multicentre cohort study from South Africa. AIDS Care, 26: 448-53.

FISCHL, J. 2013. Almost 82 percent of social workers are female and this is hurting male. [Online] Available: http://www.policymic.com/articles/30974/almost-82-percent-of-social-workers-are-femaleand-this-is-hurting-men [Accessed: 19/08/2020].

FOSTER, G. 2005. Under the radar - Community safety nets for children affected by HIV/AIDS in poor households in sub-Saharan Africa. Prepared for UNRISD programme on community responses to HIV and AIDS.

FOUCHÉ, C.B. \& SCHURINK, W. 2011. Qualitative research designs. In: DE VOS, A.S., STRYDOM, H., FOUCHé, C.B. \& DELPORT, C.S.L. (eds.). Research at grass Roots: For the social sciences and human service professions. $4^{\text {th }}$ ed. Pretoria: Van Schaik Publishers.

GERMAIN, C. B. 1991. Human behavior in the social environment: An ecological view. New York: Columbia University Press.

GICHARU, P.W., MWANIKI, B., KIBUI, A., GICHUHI, L. \& KAHIGA, R.W. 2015. Effect of HIV/AIDS on academic performance of preschool children in Kijabe location, Kiambu county, Kenya. International Journal of Scientific Research and Innovative Technology, 2(3):17-25.

GRAY, M. 2006. The progress of social development in South Africa. International Journal of Social Welfare, 15(1):52-63.

GREEFF, M. 2011. Information collection: Interviewing. In: DE VOS, A.S., STRYDOM, H., FOUCHé, C.B. \& DELPORT, C.S.L. (eds.). Research at grass roots for the social sciences and human service professions.( 4th ed). Pretoria: Van Schaik.

GREENE, R. R. 2000. Human behavior theory and social work practice. $2^{\text {nd }}$ ed. Edison, NJ: Aldine Transactions.

HALL, K. 2012. Income poverty, unemployment and social grants. In: HALL, K., WOOLARD, I., LAKE, L. \& SMITH, C. (eds.). South African Child Gauge. University of Cape Town: Children's Institute.

JAMIESON, L. \& BERRY, L. 2012. Children's Act guide for drop-in-centre managers. University of Cape Town: Children's Institute.

KELLERMAN, S.E., SUGANDHI, N., LUO, C., MCCLURE, C. \& YOGEV, R. 2013. Addressing and improving the continuum of care for HIV-affected children: challenges and solutions. AIDS Journal, 27(2):135-137.

LOWENTHAL, E.D., BAKEERA-KITAKA, S., MARUKUTIRA, T., CHAPMAN, J., GOLDRATH, K. \& FERRAND, R.A. 2014. Perinatally acquired HIV infection in adolescents from sub-Saharan Africa: A review of emerging challenges. Lancet Infectious Diseases, 14:627-639.

MCNAIRY, M.L., LAMB, M.R., CARTER, R.J., FAYORSEY, R., TENE, G., MUTABAZI, V., GUSMAO, E., PANYA, M., SHERIFF, M. \& ABRAMS, E.J. 2013. Retention of HIV-infected children on antiretroviral treatment in HIV care and treatment programs in Kenya, Mozambique, Rwanda, and Tanzania. Journal of Acquired Immune Deficiency Syndromes, 62(3):01-21.

MEYERS, T., MOUlTRIE, H., NAIDOO, K., COTTON, M., ELEY, B. \& SHERMAN, G. 2007. Challenges to Pediatric HIV Care and Treatment in South Africa. The Journal of Infectious Diseases, 196(3):474-481.

MIDGLEY, G. 2003. Systems thinking. London: Sage. 
MILLER, J.H. \& PAGE, S.E. 2007. Complex adaptive systems. An introduction to computational models of social life. Princeton: Princeton University Press.

MOKGATLE, M.M. \& MADIBA, P. 2015. The burden of disease on HIV-infected orphaned and nonorphaned children accessing primary health facilities in a rural district with poor resources in South Africa: a cross-sectional survey of primary caregivers of HIV-infected children aged 5-18 years. Infectious Diseases of Poverty, 4(18):02-12.

MUCHANYEREI, B. 2016. Challenges experienced by social workers in placing children living with HIV in foster care in Johannesburg. Pretoria: University of Pretoria. (MSW dissertation)

MUCHANYEREI, B. \& BILA, N. 2017. Challenges experienced by social workers in placing children living with HIV in foster care in Johannesburg. In: HENRICKSON, M. \& CHIPANTA, D. (eds.). Getting to Zero: Global social work Responds to HIV. [Online] Available: http//www.unaids.org/en/resources/documents/2017/global-social-work-responds-to-HIV_[Accessed: 19/07/2020].

NIANG, C.I. \& VAN-UFFORD, P.Q. 2002. The socio-economic impact of HIV/AIDS on children in a low prevalence context: The case of Senegal. In: CORNIA, G.A. (ed.). AIDS, public policy, and child well-being. Italy: UNICEF Innocenti Research Centre.

NIEUWENHUIS, J. 2007. Qualitative research designs and data gathering techniques. In: MAREE, K. (ed.). First steps in research. Pretoria: Van Schaik Publishers.

PETTITT, E.D., GREIFINGER, R.C., PHELPS, B.R. \& BOWSKY, S.J. 2013. Improving health services for adolescents living with HIV in Sub-Saharan Africa: A multi-country assessment. African Journal of Reproductive Health, 17(4s):17-31.

PHARAOH, R. 2005. Not business as usual - Public sector responses to HIV/AIDS in Southern Africa. Pretoria: Institute of Security Studies.

RAWAT, R., KADIYALA, S. \& MCNAMARA, P.E. 2010. The impact of food assistance on weight gain and disease progression among HIV-infected individuals accessing AIDS care and treatment services in Uganda. BMC Public Health, 10(316):02-08.

REGIONAL PSYCHOSOCIAL SUPPORT INITIATIVE (REPSSI). 2016. Mainstreaming psychosocial care and support into home-based care programmes - A guide for practitioners working with children and families affected by HIV and AIDS. Johannesburg: REPSSI \& International Federation of Red Cross and Red Crescent Societies.

RICHTER, L., BEYRER, C., KIPPAX, S. \& HEIDARI, S. 2010. Visioning services for children affected by HIV and AIDS through a family-centred lens. Journal of the International AIDS Society, 13(2):2637.

RWEMISISI, J., WOLFF, B., COUTINHO, A., GROSSKURTH, H., \& WHITWORTH, J. 2008. What if they ask how I got it? Dilemmas of disclosing parental HIV status and testing children for HIV in Uganda. Health Policy and Planning, 23(1):36-42.

SCHULTZ, P. 2015. Social auxiliary work. In: SCHENCK, R. (ed.). Introduction to social work in the South African context. South Africa: Oxford University Press.

REPUBLIC OF SOUTH AFRICA(RSA). 1998. Social Work Amendment Act 102 of 1998. Government Gazette, 19516. Pretoria: Government Printer.

SCOTT, K., BECKHAM, S.W, GROSS, M., PARIYO, G., RAO, K.D., COMETTO, G., \& PERRYET, H.B. 2018. What do we know about community-based health worker programs? A systematic review of existing reviews on community health workers. Resources for Health, 16(1):1-17.

REPUBLIC OF SOUTH AFRICA (RSA).1978. Social Service Professions Amend Act 110 of 1978, as amended. Government Gazette, 36877. Pretoria: Government Printer. 
SOUTH AFRICAN NATIONAL AIDS COUNCIL (SANAC). 2017. National Strategic Plan 20172022. Pretoria: SANAC.

STATISTICS SOUTH AFRICA (STATS SA). 2016. Mid-year population estimates, 2016. [Online] Available: https://www.statssa.gov.za/publications/P0302/P03022016.pdf [Accessed: 23/07/2020].

STATISTICS SOUTH AFRICA (STATS SA). 2018. Mid-year population estimates, 2018. [Online] Available: http://www.statssa.gov.za/publications/P0302/P03022018.pdf [Accessed: 13/06/2020].

STRUWIG, F.W. \& STEAD, G.B. 2001. Planning, designing and reporting research. Cape Town: Research Education South Africa.

REPUBLIC OF SOUTH AFRICA (RSA). 2005. Children's Act No 38 of 2005, as amended. Government Gazette, 28944. Pretoria: Government Printer.

UNITED NATIONS PROGRAMME ON HIV/AIDS (UNAIDS). 2013. Report on the Global AIDS Epidemic. New York: World Health Organization. [Online] Available: http://www.unaids.org/en/media/unaids/contentassets/documents/epidemiology/2013/gr2013/UNAIDS _Global_Report_2013_en.pdf [Accessed: 03/08/2020].

UNITED NATIONS PROGRAMME ON HIV/AIDS (UNAIDS). 2015. GAP report. [Online] Available: http://www.unaids.org/sites/default/files/media_asset/UNAIDS_Gap_report_en.pdf 10/04/2020].

UNITED NATIONS PROGRAMME ON HIV/AIDS (UNAIDS). 2019. Report on the global AIDS epidemic. New York: World Health Organization.

UNITED NATIONS INTERNATIONAL CHILDREN'S EMERGENCY FUND (UNICEF). 2013. Towards an AIDS-free generation. Children and AIDS. Sixth Stocktaking Report. New York: UNICEF.

VRANDA, M.N. \& MOTHI, S.N. 2013. Psychosocial issues of children infected with HIV/AIDS. Indian Journal of Psychological Medicine, 35(1):19-22.

WARWICK, J.K. 2013. An explorative study of the experiences and needs of foster carers of HIV positive children in the Western Cape, South Africa. Cape Town: University of Cape Town (MSocSc dissertation)

WORLD HEALTH ORGANIZATION (WHO). 2009. Guidelines for an integrated approach to the nutritional care of HIV-infected children (6 months-14 years): Handbook, chart booklet and guideline for country adaptation. Geneva: WHO. [Online] Available: http://www.who.int/nutrition/publications/hivaids/9789241597524/en/ [Accessed: 12/08/2020].

WORLD HEALTH ORGANIZATION. 2010. Life Skills education for children and adolescents in schools - Introduction and guidelines to facilitate the development and implementation of life skills programmes. Geneva: World Health Organization.

WORLD HEALTH ORGANIZATION. 2018. HIV self-testing strategic framework. A guide for planning, introducing, and scaling up. Geneva: WHO. [Online] Available: https://www.afro.who.int/sites/default/files/2019-12/9789241514859-eng.pdf [Accessed: 26/02/2020].

YEAP, A.D., HAMILTON, R., CHARALAMBOUS, S., DWADWAB, T., CHURCHYARD, J.G., GEISSLERA, P.W \& GRANTA, A.D. 2010. Factors influencing uptake of HIV care and treatment among children in South Africa - A qualitative study of caregivers and clinic staff. AIDS Care,22(9):1101-1107. [Online] http://www.tandfonline.com/doi/abs/10.1080/09540121003602218\#.VfEEDhGqqkp Available: 09/01/2020]. 